\title{
COMMENTARY
}

\section{Continuous glucose sensors for glycaemic control in the ICU: have we arrived?}

\author{
Dieter Mesotten* \\ See related research by Blixt et al., http://ccforum.com/content/17/3/R87
}

\begin{abstract}
Dr Blixt and colleagues show in an elegant pilot study that the continuous measurement of glucose in venous blood by microdialysis in a central venous catheter is feasible in critically ill patients. The performance of this type of continuous glucose monitoring device equals the performance of the commonly used handheld blood glucose meters. But are we, as ICU physicians and nurses, now ready to implement such continuous blood glucose sensors into the daily practice of the ICU? The only yardstick to this is "are these devices truly helping us ...in our critically ill patients".
\end{abstract}

\section{Introduction}

Tight blood glucose control, within the range of fasting blood glucose levels, reduced morbidity in critically ill patients in the setting of well-controlled single-centre studies. Tight blood glucose control also lowered mortality in adult and paediatric patients after cardiac surgery $[1,2]$. In contrast, the large, international multicentre clinical NICE-SUGAR study showed increased mortality in the patients undergoing tight blood glucose control [3]. Due to NICE-SUGAR's pragmatic nature, variations in the essential parts of glycaemic control were allowed [4]. Particularly, all sorts of glucose measurement methodologies were used: handheld blood glucose meters, blood gas analysers and central laboratory measurements. Blood for the measurement could be of arterial, venous or capillary origin.

Two major conclusions were drawn from this NICESUGAR trial [4]. First, glycaemic control must be important in critically ill patients because its manipulation may decrease or increase mortality. Second, more attention is

*Correspondence: dieter.mesotten@med.kuleuven.be

Department of Intensive Care Medicine, KU Leuven, University Hospitals Leuven, Herestraat 49, B-3000 Leuven, Belgium needed for the technological aspects of blood glucose control, notably the blood glucose measurements and the glycaemia control systems, that give advice on the insulin dosage [5].

Hence, continuous blood glucose monitoring (CGM) devices could become an integral part of safe and effective glycaemic control in order to provide patient benefit, while minimising the workload for the nurses.

\section{Pilot studies... and hopefully more}

The small $(n=10)$ implementation study by Dr Blixt and colleagues showed that, in patients who underwent upper abdominal surgery, the point accuracy of microdialysis CGM is in line with that of the handheld blood glucose meters, with a $95 \%$ confidence interval of $\pm 2 \mathrm{mmol} / \mathrm{l}$ $(36 \mathrm{mg} / \mathrm{dl})$ [6,7]. A similar study with the same CGM device in cardiac surgery patients yielded comparable results [8]. These results were obtained in a time period of 20 hours and a context of tolerating hyperglycaemia up to $11 \mathrm{mmol} / \mathrm{l}(198 \mathrm{mg} / \mathrm{dl})$.

Clearly, this device is meeting the criteria for safety and performance, sufficient to obtain a CE mark (Figure 1): the device is safely measuring blood glucose levels with an acceptable accuracy in the normoglycaemic and hyperglycaemic range. Are we now ready for wide CGM implementation? Probably not, for two reasons.

First, for handheld blood glucose meters, such a level of accuracy is deemed insufficient to manage tight glycaemic control $[9,10]$. For handheld blood glucose meters and the current CGM devices the 95\% confidence interval range $(36 \mathrm{mg} / \mathrm{dl})$ is larger than the range $(30 \mathrm{mg} / \mathrm{dl})$ for tight glycaemic control (80 to $110 \mathrm{mg} / \mathrm{dl}$ ). These sensors may also overestimate blood glucose levels in the hypoglycaemic zone. The presence of continuous data and the embedded trend information may compensate this moderate point accuracy in CGM sensors. If this was true, CGM should easily help us in realising tight glycaemic control while avoiding hypoglycaemia and increased blood glucose variability.

Second, the clinical evidence is still too weak. Randomised controlled trials will be required to show that these devices can deliver this ambition in ideal circumstances 


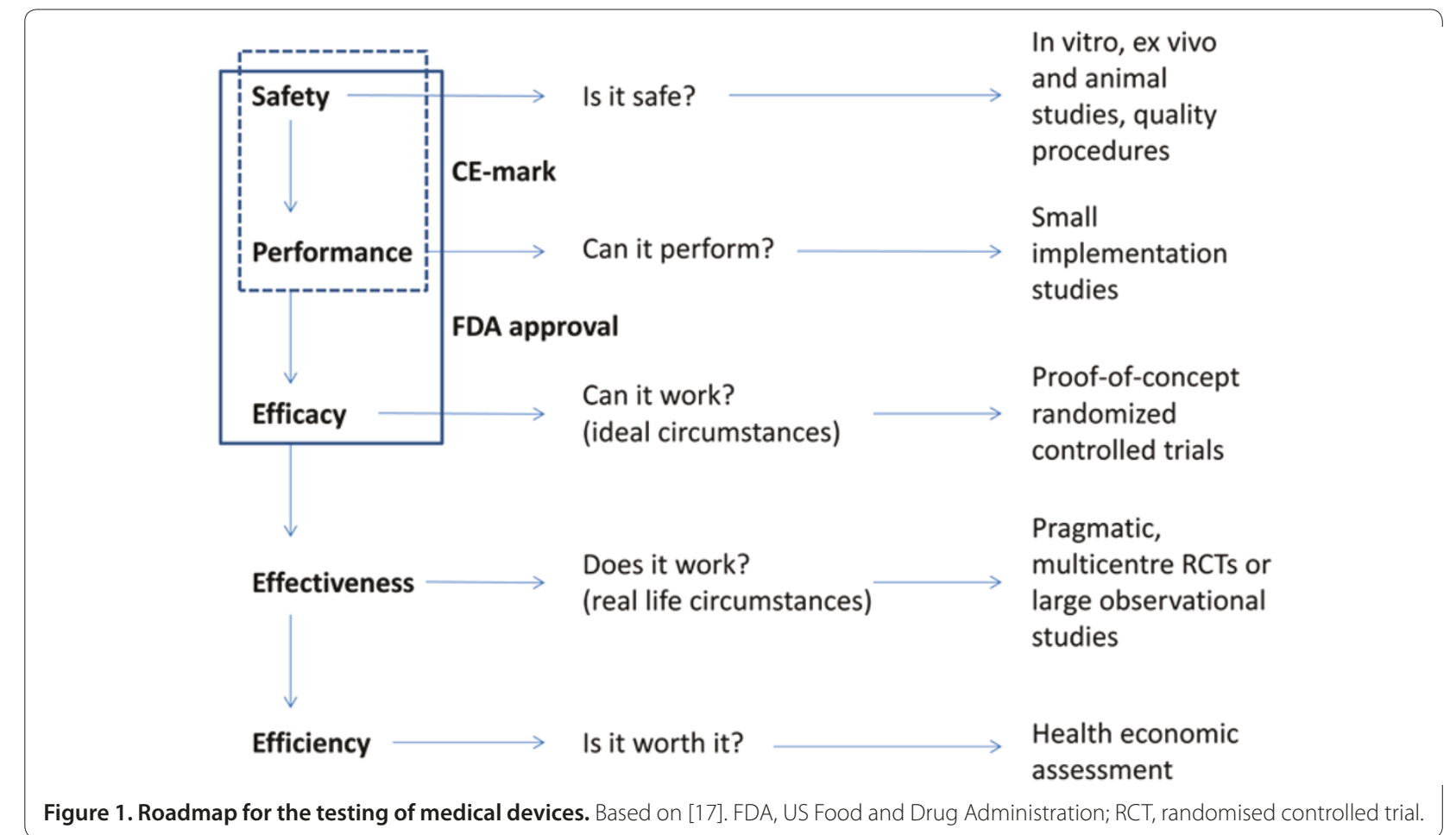

(efficacy) and in the usual clinical setting of any ICU across the globe (effectiveness). A (subcutaneous) CGM device reached similar point accuracies $(46 \mathrm{mg} / \mathrm{dl})$, but in a single-centre efficacy randomised controlled trial the device only decreased the incidence of hypoglycaemia without improving blood glucose control or variability $[11,12]$. The clinical community is now eagerly awaiting these randomised controlled trials with the newer CGM devices to decide on their applicability. The comparator in these trials should be the current gold standard of glucose measurements in arterial blood by a blood gas analyser. Additionally, change in patient-centred outcome measures of the glucose dynamics should be the focus of these trials [13].

Such a roadmap may seem tedious and expensive for CGM validation. Nevertheless, this will be essential to convince the evidence-based medicine trained physician. Moreover, healthcare payers and society will pass the final judgement: is it worth it? Otherwise, expert nurses $[1,14]$ or computerised protocols [15,16] using intermittent blood glucose measurements may remain the cost-effective gold standard.

\section{Conclusion}

The point accuracy of a near-continuous blood glucose sensor with microdialysis through a central venous line is acceptable for monitoring in the normoglycaemic and hyperglycaemic range. However, the device is currently not good enough for blood glucose management within a narrow range. The clinical benefit and cost-effectiveness of these CGM devices still have to be demonstrated against the current gold standard of intermittent arterial glucose measurements in a blood gas analyser.

\section{Abbreviations}

CGM, continuous blood glucose monitoring.

\section{Competing interests}

DM has received, through KU Leuven, speaker's honoraria and travel reimbursements from Maquet and Medtronic.

\section{Acknowledgements}

The author is a senior clinical investigator for the Research Foundation Flanders (FWO) and receives support from the Flemish Agency for Innovation by Science and Technology (IWT-TBM 100793).

\section{Published: 8 October 2013}

\section{References}

1. Van den Berghe $G$, Wouters P, Weekers F, Verwaest C, Bruyninckx F, Schetz M, Vlasselaers D, Ferdinande P, Lauwers P, Bouillon R: Intensive insulin therapy in the critically ill patients. N Eng/ J Med 2001, 345:1359-1367.

2. Vlasselaers D, Milants I, Desmet L, Wouters PJ, Vanhorebeek I, van den Heuvel I, Mesotten D, Casaer MP, Meyfroidt G, Ingels C, Muller J, Van Cromphaut S, Schetz M, Van den Berghe G: Intensive insulin therapy for patients in paediatric intensive care: a prospective, randomised controlled study. Lancet 2009, 373:547-556.

3. Finfer $S$, Chittock DR, Su SY, Blair D, Foster D, Dhingra V, Bellomo R, Cook D, Dodek P, Henderson WR, Hébert PC, Heritier S, Heyland DK, McArthur C, McDonald E, Mitchell I, Myburgh JA, Norton R, Potter J, Robinson BG, Ronco $\mathrm{JJ}$ : Intensive versus conventional glucose control in critically ill patients. NEngl J Med 2009, 360:1283-1297.

4. Van den Berghe G, Schetz M, Vlasselaers D, Hermans G, Wilmer A, Bouillon R, Mesotten D: Clinical review: Intensive insulin therapy in critically ill patients: NICE-SUGAR or Leuven blood glucose target? J Clin Endocrinol Metab 2009, 94:3163-3170. 
5. Finfer S, Wernerman J, Preiser JC, Cass T, Desaive T, Hovorka R, Joseph Jl, Kosiborod M, Krinsley JS, Mackenzie IM, Mesotten D, Schultz MJ, Scott MG, Slingerland R, Van den Berghe G, Van Herpe T: Clinical review: Consensus recommendations on measurement of blood glucose and reporting glycemic control in critically ill adults. Crit Care 2013, 17:229

6. Blixt C, Rooyackers O, Isaksson B, Wernerman J: Continuous on-line glucose measurement by microdialysis in a central vein. A pilot study. Crit Care 2013, 17:R87.

7. Vlasselaers D, Van Herpe T, Milants I, Eerdekens M, Wouters PJ, De Moor B, Van den Berghe G: Blood glucose measurements in arterial blood of intensive care unit patients submitted to tight glycemic control: agreement between bedside tests. J Diabetes Sci Technol 2008, 2:932-938

8. Schierenbeck F, Owall A, Franco-Cereceda A, Liska J: Evaluation of a continuous blood glucose monitoring system using a central venous catheter with an integrated microdialysis function. Diabetes Technol Ther 2013, 15:26-31.

9. Scott MG, Bruns DE, Boyd JC, Sacks DB: Tight glucose control in the intensive care unit: are glucose meters up to the task? Clin Chem 2009, 55:18-20.

10. Kanji S, Buffie J, Hutton B, Bunting PS, Singh A, McDonald K, Fergusson D, McIntyre LA, Hebert PC: Reliability of point-of-care testing for glucose measurement in critically ill adults. Crit Care Med 2005, 33:2778-2785.

11. Holzinger U, Warszawska J, Kitzberger R, Wewalka M, Miehsler W, Herkner H, Madl C: Real-time continuous glucose monitoring in critically ill patients: a prospective randomized trial. Diabetes Care 2010, 33:467-472.
12. Brunner R, Adelsmayr G, Herkner H, Madl C, Holzinger U: Glycemic variability and glucose complexity in critically ill patients: a retrospective analysis of continuous glucose monitoring data. Crit Care 2012, 16:R175.

13. Van Herpe T, Mesotten D: Blood glucose measurements in critically ill patients. J Diabetes Sci Technol 2012, 6:22-28.

14. Krinsley JS: Effect of an intensive glucose management protocol on the mortality of critically ill adult patients. Mayo Clin Proc 2004, 79:992-1000.

15. Van Herpe T, Mesotten D, Wouters PJ, Herbots J, Voets E, Buyens J, De Moor B, Van den Berghe G: LOGIC-insulin algorithm-guided versus nurse-directed blood glucose control during critical illness: the LOGIC-1 single-center, randomized, controlled clinical trial. Diabetes Care 2013, 36:188-194.

16. Cordingley JJ, Vlasselaers D, Dormand NC, Wouters PJ, Squire SD, Chassin LJ, Wilinska ME, Morgan CJ, Hovorka R, Van den Berghe G: Intensive insulin therapy: enhanced model predictive control algorithm versus standard care. Intensive Care Med 2009, 35:123-128.

17. Haynes B: Can it work? Does it work? Is it worth it? The testing of healthcare interventions is evolving. BMJ 1999, 319:652-653.

doi:10.1186/cc12804

Cite this article as: Mesotten D: Continuous glucose sensors for glycaemic control in the ICU: have we arrived? Critical Care 2013, 17:1004. 